\title{
T lymphocyte responses against hepatitis B virus-related hepatocellular carcinoma induced by adenovirus vaccine encoding $\mathbf{H B x}$
}

\author{
YUHUA LI $^{1,2^{*}}$, PING CHENG $^{1 *}$, YANJUN WEN $^{1 *}$, PING CHEN $^{1,2^{*}}$, LI YANG $^{1}$, XIA ZHAO $^{1}$, \\ HUIMIN LV ${ }^{1}$, QINGLI QUAN ${ }^{1}$, YONGLIN WU ${ }^{2}$, HUIQIANG YANG ${ }^{2}$, JIE LIU ${ }^{2}$, XUERU WEN ${ }^{2}$, \\ NINA LIU ${ }^{2}$, ZHUANG KANG ${ }^{2}$, SHAN LUO $^{1,2}$, LIAN WANG $^{3}$ and YUQUAN WEI ${ }^{1}$ \\ ${ }^{1}$ State Key Laboratory of Biotherapy, West China Hospital and College of Life Science, Sichuan University; \\ ${ }^{2}$ Chengdu Institute of Biological Products; ${ }^{3}$ Department of Oral Pathology, West China \\ College of Stomatology, Sichuan University, Chengdu 610041, P.R. China
}

Received June 9, 2010; Accepted August 13, 2010

DOI: $10.3892 /$ ijmm_00000536

\begin{abstract}
HBx is an oncogenic tumor-associated antigen and is dominantly expressed in hepatitis and hepatoma tissues, the induction of active cellular responses against $\mathrm{HBx}$ should be a promising approach for the treatment of hepatitis $B$ virus-related hepatocellular carcinoma. The present study was designed to test whether a replication-defective adenovirus vaccine expressing $\mathrm{HBx}$ antigen could be effectively used in the immunotherapy of hepatocellular carcinoma. To validate the possibility, we developed a novel HBx-positive hepatocellular carcinoma in mice by inoculated the pcDNA-HBx transfected Hepa1-6 cells subcutaneously into the right flank of mice. We found that immunotherapy with Ad-HBx was effective at both protective and therapeutic antitumor immunity in the hepatoma models in immune-competent mice. Histological examination revealed that Ad-HBx treatment led to significantly increased induction of apoptosis, tumor necrosis, and elevated $\mathrm{CD} 8^{+}$lymphocyte infiltration. In addition, the induction efficacy of the CTL response is dramatically enhanced by immunotherapy. Cytokine analysis comfirmed that the antitumor efficacy of Ad-HBx may mostly result from cellular immunity. Our findings may prove useful in development of adenovirus vaccine based on $\mathrm{HBx}$ antigen to the treatment of $\mathrm{HBV}$ associated hepatocellular carcinoma.
\end{abstract}

Correspondence to: Professor Yuquan Wei, State Key Laboratory of Biotherapy, West China Hospital, West China Medical School, Sichuan University, 1\# Keyuan Road 4, Gaopeng Street, High Technological Development Zone, Chengdu 610041, P.R. China E-mail: yuquawei@vip.sina.com

${ }^{*}$ Contributed equally

Key words: immunotherapy, CTLs, hepatitis B virus, HBx, hepatocellular carcinoma

\section{Introduction}

Hepatitis B virus (HBV) is a small DNA virus belonging to the family hepadnaviridae which replicates the genome by reverse transcription (1). HBV infection are strongly associated with the development of hepatocellular carcinoma (HCC), which is one of the most common and recurrent malignancies worldwide (2). Hepatic resection and liver transplantation is the choice of treatment for hepatocellular carcinoma, however, few patients have the opportunity to undergo these procedures. In addition, high recurrent rate after resection and resistance to conventional treatments have rendered the disease a very serious health problem (3). Thus, the development of novel strategies against HCC is much needed (4-6).

Of the interventions designed to treat cancer, immunotherapy with CTLs is increasingly being recognized as one of the most efficient strategies (7). One key factor in the development of a CTL-based therapy is to develop epitopebased vaccines that elicit this response $(8,9)$. Virus-associated malignancies offer a distinct advantage in this regard since therapy can be directly targeted toward viral antigens expressed by the tumor (10). Previous studies have shown that virus antigen-based vaccines have significant results in both animal models and patients, which strongly suggest that virus-specific CTLs might be the important elements that regulate the immune control of virus-associated malignancies (11).

$\mathrm{HBx}$, an $\mathrm{HBV}$-encoded protein with multiple functions in cellular signal transduction, transcription pathways and HBV replication, has been recognized as an oncogene and closely relevant with the development of HBV-mediated HCC $(12,13)$. It has been demonstrated that $\mathrm{HBx}$ expression is present in $\sim 80 \%$ of the HCC cases including both carcinomas and pericancerous liver tissues (14). Previous studies have showed that vaccines based on HBx full-length sequence or specific epitopes could elicit specific antitumor immune responses (15-17).

We developed a replication-defective adenovirus vaccine expressing $\mathrm{HBx} \mathrm{Ag}$ for the treatment of $\mathrm{HBx}$-positive 
hepatoma. Our results demonstrated that the vaccine could successfully elicit $\mathrm{HBx}$-specific $\mathrm{CD}^{+} \mathrm{T}$ lymphocytes and induce significant antitumor effects.

\section{Materials and methods}

Cell lines and mice. 293A (human embryonic kidney), Hepa1-6 (HCC derived from C57 BL/6 mouse) cell lines were obtained from the American Type Culture Collection. Cells were cultured in DMEM supplemented with $10 \%$ fetal bovine serum (FBS), maintained in a $37^{\circ} \mathrm{C}$ incubator with a humidified $5 \%$ $\mathrm{CO}_{2}$ atmosphere. Female C57BL/6 mice aged 6-8-weeks were obtained from Laboratory Animal Center of Sichuan University and maintained in pathogen-free conditions. All procedures were reviewed and approved by the institute's Animal Care and Use Committee.

Generation of recombinant adenovirus. Recombinant adenovirus vectors carrying $\mathrm{HBx}$ gene (Ad-HBx) was generated with a ViraPower adenovirus expression system (Invitrogen) as described previously (18). The recombinant adenovirus without foreign gene (Ad-null) served as a control. All virus particles were amplified in HEK 293A cells and purified by cesium chloride gradient centrifugation, titrated as PFU per milliliter and stored at $-80^{\circ} \mathrm{C}$.

Plasmid construction and stable transfection. HBx expression plasmids were constructed as follows: HBx was amplified by polymerase chain reaction (PCR) with upstream primer 5'-TTA ACCATGGCTGCTAGGCTGTGCTGC-3' and downstream primer 5'-GGCTCGAGTTAGGCAGAGGTGAAAAAG TTG-3'. The PCR product was digested with NcoI and $X h o I$, and was inserted into eukaryotic expression vector pcDNA3.1 (+) (Invitrogen). Verification of the recombinant construct was performed by DNA sequencing. The plasmid was designated as pcDNA-HBx. pcDNA3.1 or pcDNA-HBx was transfected into Hepa1-6 cells using Lipofectamine ${ }^{\mathrm{TM}}$ 2000 (Invitrogen). At 48-h post-transfection, cells were split at a 10:1 ratio and cultured in the presence of $400 \mu \mathrm{g} / \mathrm{ml} \mathrm{G} 418$. After 28 days in selective medium, G418-resistant colonies were isolated. Then, the expression of HBx was detected by reverse transcription-polymerase chain reaction (RT-PCR) and Western blotting.

Vaccine immunization. Mice were immunized s.c. with normal saline (NS) (100 $\mu 1$ each), Ad-null $\left(10^{8} \mathrm{pfu} / 100 \mu \mathrm{l}\right.$ each) or Ad-HBx $\left(10^{8} \mathrm{pfu} / 100 \mu \mathrm{l}\right.$ each $)$ once weekly for 4 weeks. One week after the final immunization, $2 \times 10^{6}$ Hepa1-6/HBx cells were s.c. injected into the right flank. For an investigation of the therapeutic effect against the established tumors, ten mice in each group were treated with subcutaneous injection of the adenovirus vaccines or NS once weekly for 4 weeks on day 7 after subcutaneous introduction of $2 \times 10^{6}$ Hepa1-6/HBx cells. Tumor dimensions were measured with calipers every 3 days and tumor volumes were calculated according to the following formula: $V=0.52 \times$ length $x$ width ${ }^{2}$. The mice were sacrificed when they became moribund. The date of sacrifice was recorded to calculate the survival time.

Quantitative assessment of apoptosis. Tumor species were prepared as described previously (19). The presence of apoptotic cells within the tumor sections was determined using the In Situ Cell Death detection kit (DeadEnd ${ }^{\mathrm{TM}}$ Fluorometric TUNEL System, Promega), according to the manufacturer's protocol. In tissue sections, four equal-sized fields were randomly chosen and analyzed. The apoptotic index (AI) was defined as follows: AI $(\%)=100 \mathrm{x}$ apoptotic cells/total tumor cells.

Histological analysis. Tumors from each group were embedded in paraffin, sections 3-5 $\mu \mathrm{m}$ were stained with hematoxylin and eosin $(\mathrm{H} \& \mathrm{E})$. Immunofluorescence staining was used to determine the infiltration of lymphocytes in the tumor tissue. Frozen sections were blocked (10\% FBS, 3\% BSA) for $30 \mathrm{~min}$ before staining with anti-CD4 (FITC conjugate) and antiCD8 (Cy5PE conjugate) monoclonal antibody. Fluorescence was visualized, and images were captured with fluorescence microscopy (Leica).

Flow cytometry. Splenocytes were isolated as described above and placed in ice-cold PBS supplemented with 5\% FBS and $0.1 \%$ sodium azide. Then the cell suspensions were stained with a combination of fluorochrome-conjugated antibodies, including fluorescein isothiocyanate (FITC)-conjugated antimouse CD4 and phycoerythrin (PE)-conjugated anti-mouse CD8, cyanine5 (Cy5)-conjugated anti-mouse CD3. After staining, multiple-color flow analyses were performed using flow cytometer (Beckman Coulter). Twenty thousand events were recorded per sample in an appropriately gated region (lymphocyte gate).

Cytotoxicity assay. A 4-h ${ }^{51} \mathrm{Cr}$ release assay was performed to evaluate the adaptive cellular immune response as described previously (20). Briefly, four weeks after the final immunization, three mice in each group were sacrificed, spleen $\mathrm{T}$ lymphocytes obtained from the mice were isolated from single-cell suspensions with Nylon Fiber Column T (LType, Wako) as CTL effector cells. Hepa1-6/HBx cells $\left(1 \times 10^{6}\right)$ as target cells were incubated at $37^{\circ} \mathrm{C}$ with $200 \mu \mathrm{Ci}$ sodium chromate (Sigma) for $2 \mathrm{~h}$. After washing 3 times, ${ }^{51} \mathrm{Cr}$-labeled target cells were seeded into 96-well V-bottomed plates at $1 \times 10^{4}$ cells per well in $100 \mu 1$ complete RPMI-1640. Effector cells from spleen were seeded into triplicate wells containing the target cells at various effector/target (E:T) cell ratios, making a final volume of $200 \mu 1$. Plates were incubated at $37^{\circ} \mathrm{C}$ in a humidified incubator with $5 \% \mathrm{CO}_{2}$ for $4 \mathrm{~h}$. Plates were centrifuged, and the supernatant $(100 \mu 1)$ was removed from each well to assess the ${ }^{51} \mathrm{Cr}$ release using a gamma radiation counter (Perkin-Elmer). The activity was calculated by the formula: \%cytotoxicity $=[$ (experimental releasespontaneous release)/(maximum release-spontaneous release)] $\mathrm{x} 100 \%$.

ELISA. IFN- $\gamma$, IL-2 and IL-4 were determined as previously described (21). Briefly, splenocytes obtained from the immunized or control mice were prepared as described above, and were plated at $2 \times 10^{5}$ cells per well in flat-bottom microtiter plates. These splenocytes were restimulated with Ad-HBx ( $\left.4 \times 10^{6} \mathrm{PFU}\right)$. After $72 \mathrm{~h}$ at $37^{\circ} \mathrm{C}, 100 \mu 1$ of supernatant was harvested and tested for IFN- $\gamma$, IL-2 and IL-4 by ELISA kit (BD PharMingen, San Diego, CA). 

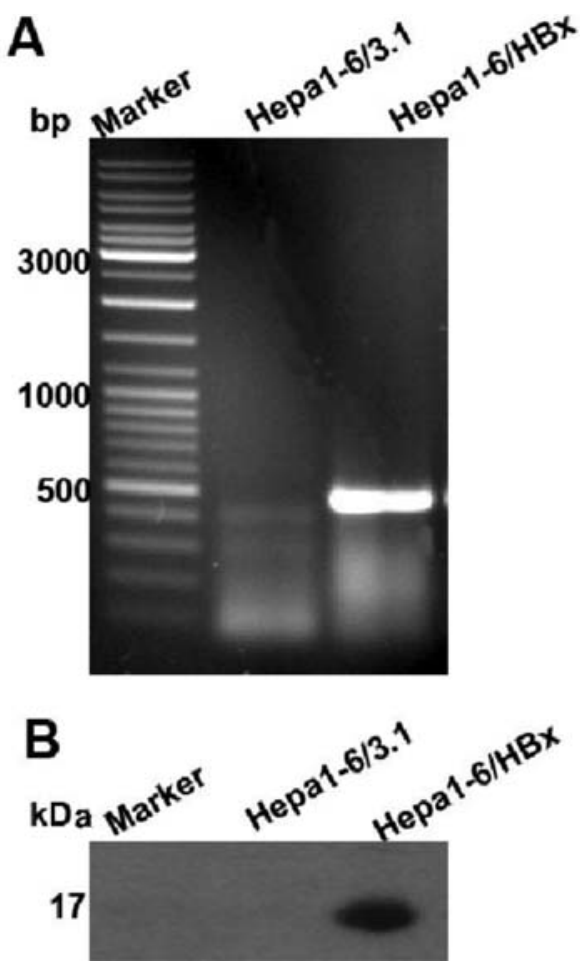

Figure 1. The expression of HBx in a stable cell line. (A) RT-PCR result of Hepa1-6 cells stably transfected with pcDNA-HBx or pcDNA3.1. (B) Western blot analysis of HBx protein in Hepa1-6 cells stably transfected with pcDNA-HBx.

In vivo depletion of immune cell subsets. Immune cell subsets were depleted as described previously $(22,23)$. Mice were injected intraperitoneally with $500 \mu \mathrm{g}$ of either the anti-CD4 (clone GK 1.5, rat IgG), anti-CD8 (clone 2.43, rat IgG), antinatural killer (NK) (clone PK136) monoclonal antibody $(\mathrm{mAb})$, or isotype controls 1 day before immunization and then twice per week for 3 weeks. Mice were immunized as described above and $\sim 2 \times 10^{6}$ Hepa $1-6 / \mathrm{HBx}$ cells were challenged after the fourth immunization. These hybridomas were obtained from the American Type Culture Collection (Manassas, VA). The depletion of $\mathrm{CD}^{+}, \mathrm{CD}^{+}$, and NK cells was consistently $>98 \%$, as determined by flow cytometry.

Statistical analysis. Statistical evaluations of numerical variables were performed using One-Way ANOVA test in multiple groups. For the survival time of animals, KaplanMeier curves were established for each group, and the survivals were compared by means of the log-rank test. Significance was defined as $\mathrm{P}<0.05$.

\section{Results}

Establishment of a mouse hepatoma cell line expressing HBx. To investigate the antituomr effect of adenovirus vaccine expressing $\mathrm{HBx}$ in immune-competent mice, eukaryotic plasmid expressing $\mathrm{HBx}$ was constructed and was stably transfected into mouse hepatoma Hepa1-6 cells. The expression of HBx in the stable cell line was detected by RT-PCR (Fig. 1A) and Western blotting (Fig. 1B).

Induction of protective antitumor immunity. To examine whether tumorigenesis could be inhibited by adenoviral vaccines expressing $\mathrm{HBx}, \mathrm{C} 57 \mathrm{BL} / 6$ mice were immunized once weekly for 4 weeks. As shown in Fig. 2A, Ad-HBx treatment significantly delay the growth of tumors as compared
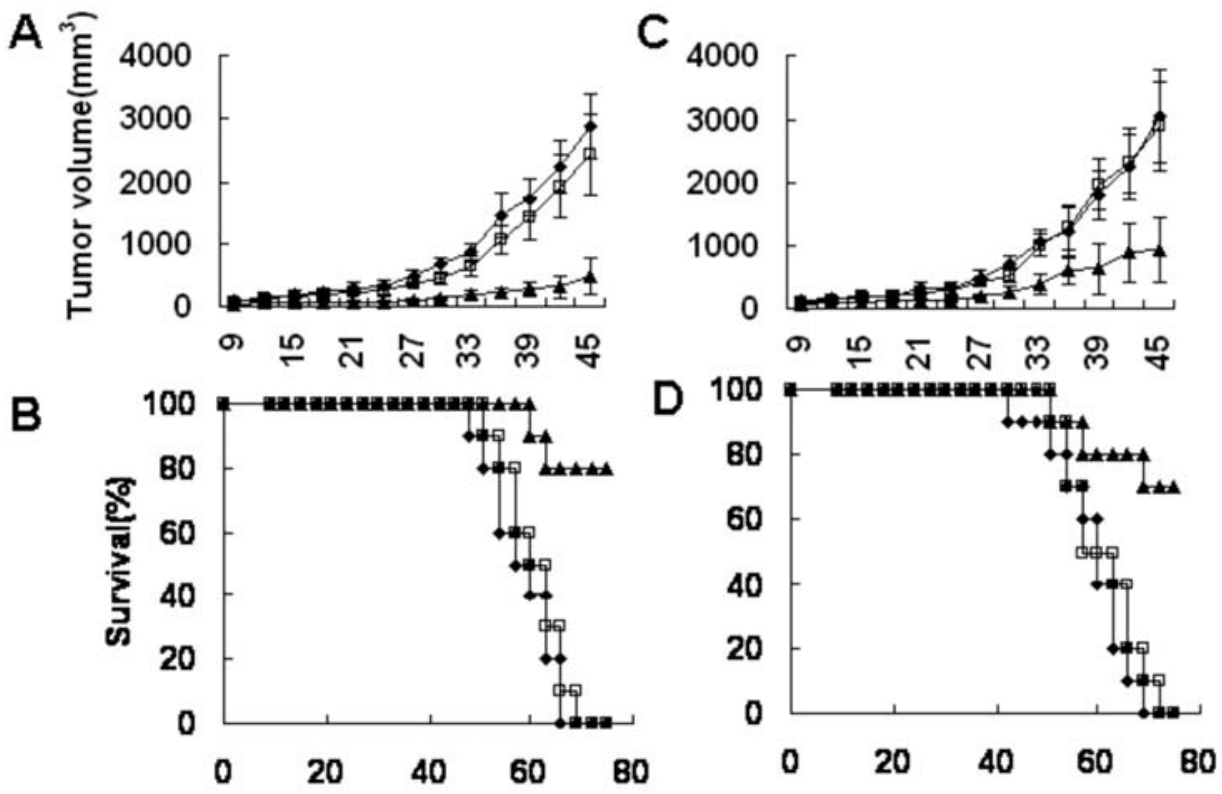

Figure 2. Induction of protective and therapeutic antitumor immunity. For an investigation of the protective antitumor effect of the adenovirus vaccine, ten mice in each group were immunized s.c. with $10^{8}$ pfu of Ad-HBx ( $\left.\mathbf{\Delta}\right)$ or Ad-null ( $\square$ ) or normal saline( $\bullet$ ) once a week for 4 weeks. Mice were then challenged with $2 \times 10^{6}$ Hepa1-6/HBx cells s.c. 1 week after the fourth immunization. Efficient tumor growth inhibition $(\mathrm{A}, \mathrm{P}<0.01)$ and a significant increase in survival can be observed in the Ad-HBx immunized group $(B, P<0.01)$. To investigate the therapeutic antitumor effect of the vaccine, tumor-bearing mice $(10$ mice in each group) were treated with s.c. injection of $10^{8}$ pfu of Ad-HBx ( $\left.\mathbf{\Delta}\right)$, Ad-null ( $\square$ ) or normal saline $(\bullet)$ once weekly for 4 weeks starting at day 7 after tumor cell inoculation. Treatment with Ad-HBx significantly suppressed tumor growth $(\mathrm{C}, \mathrm{P}<0.01)$ and resulted in a significantly prolonged survival $(\mathrm{D}, \mathrm{P}<0.01)$. Point, average tumor volume; bar $\pm \mathrm{SD}$. 

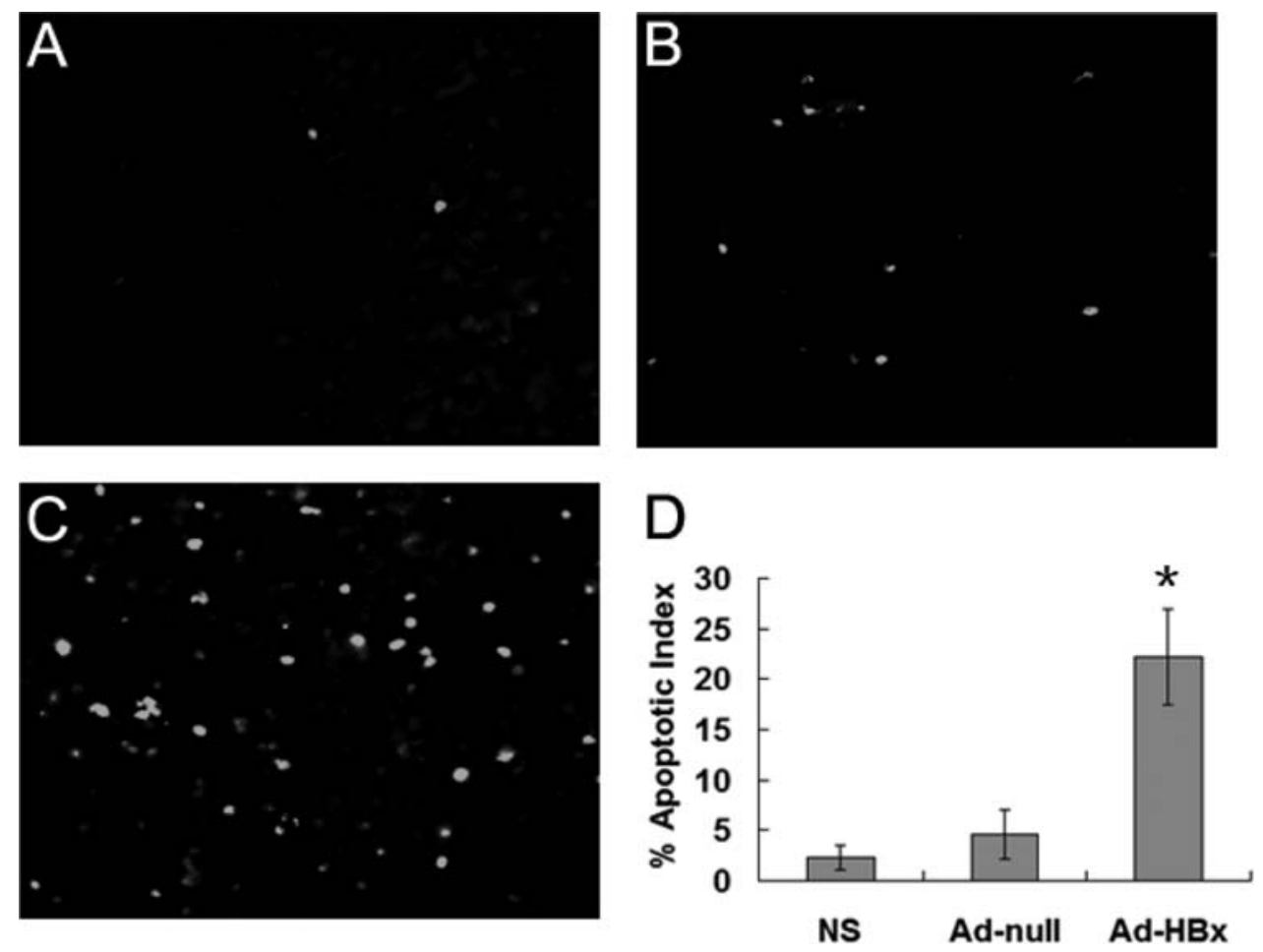

Figure 3. Induction of tumor cell apoptosis. Apoptotic tumor cells within tumor tissues were elevated by TUNEL assays, as described in Materials and methods. Representative sections from tumor tissues are presented: (A) NS (normal saline); (B) Ad-null; and (C) Ad-HBx. The treatment with Ad-HBx showed an apparent increment of apoptotic cells within the tumor tissues. Bar represented apoptotic index within tissues (D). " $\mathrm{P}<0.01$, significantly different from the normal saline (NS) or Ad-null groups.

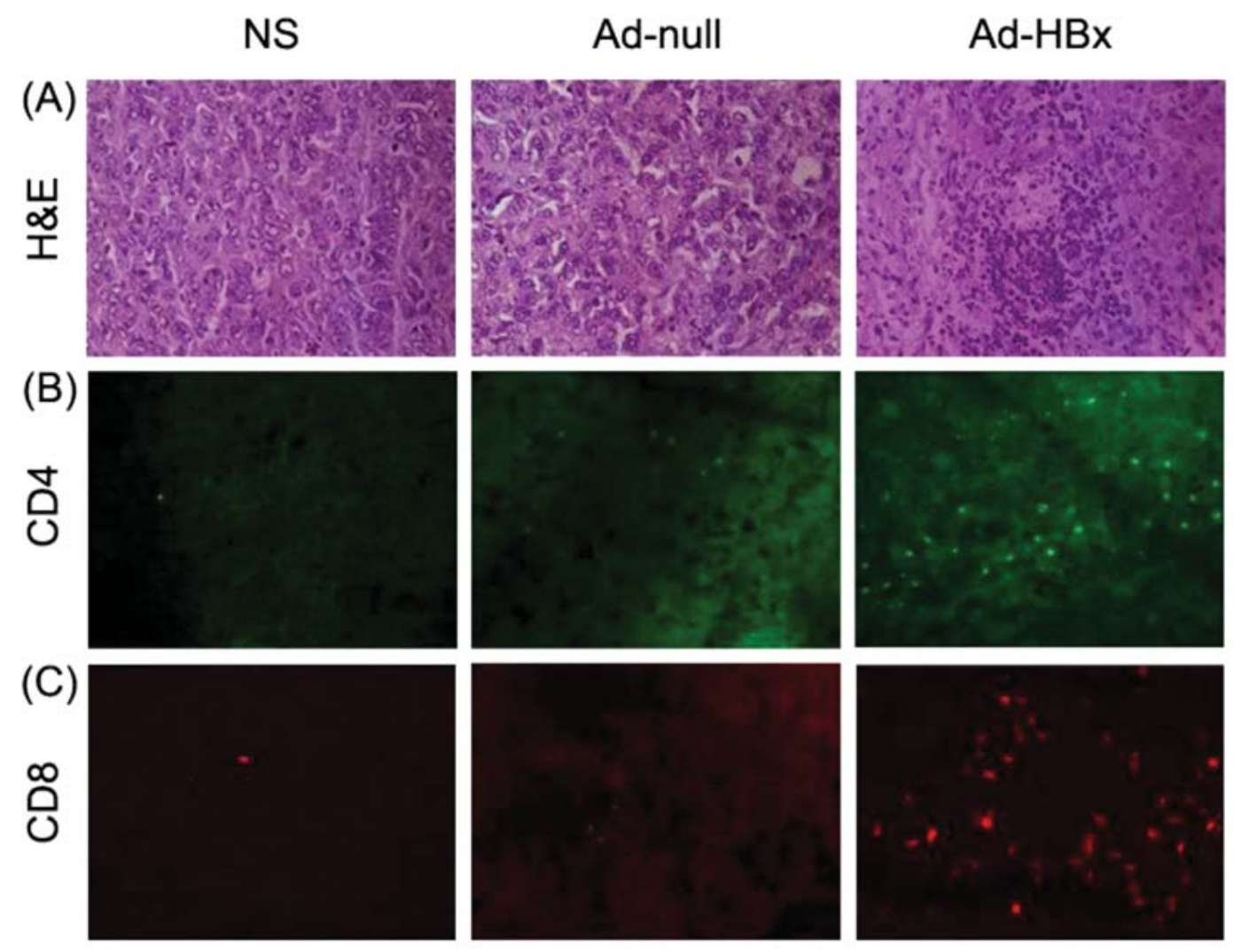

Figure 4. Histological and fluorescence analysis of infiltrated lymphocytes. (A) Histological examination of tumors by H\&E staining was performed. Lymphocyte infiltration was significantly enhanced in the margin and central regions in Ad-HBx treated group. FITC-conjugated Anti-CD4 (B) and Cy5PEconjugated anti-CD8 (C) monoclonal antibodies were used to detect lymphocytes infiltrated into tumors in situ. Our results demonstrated that the infiltrated lymphocytes were mainly $\mathrm{CD} 8^{+}$cytotoxic lymphocytes. 


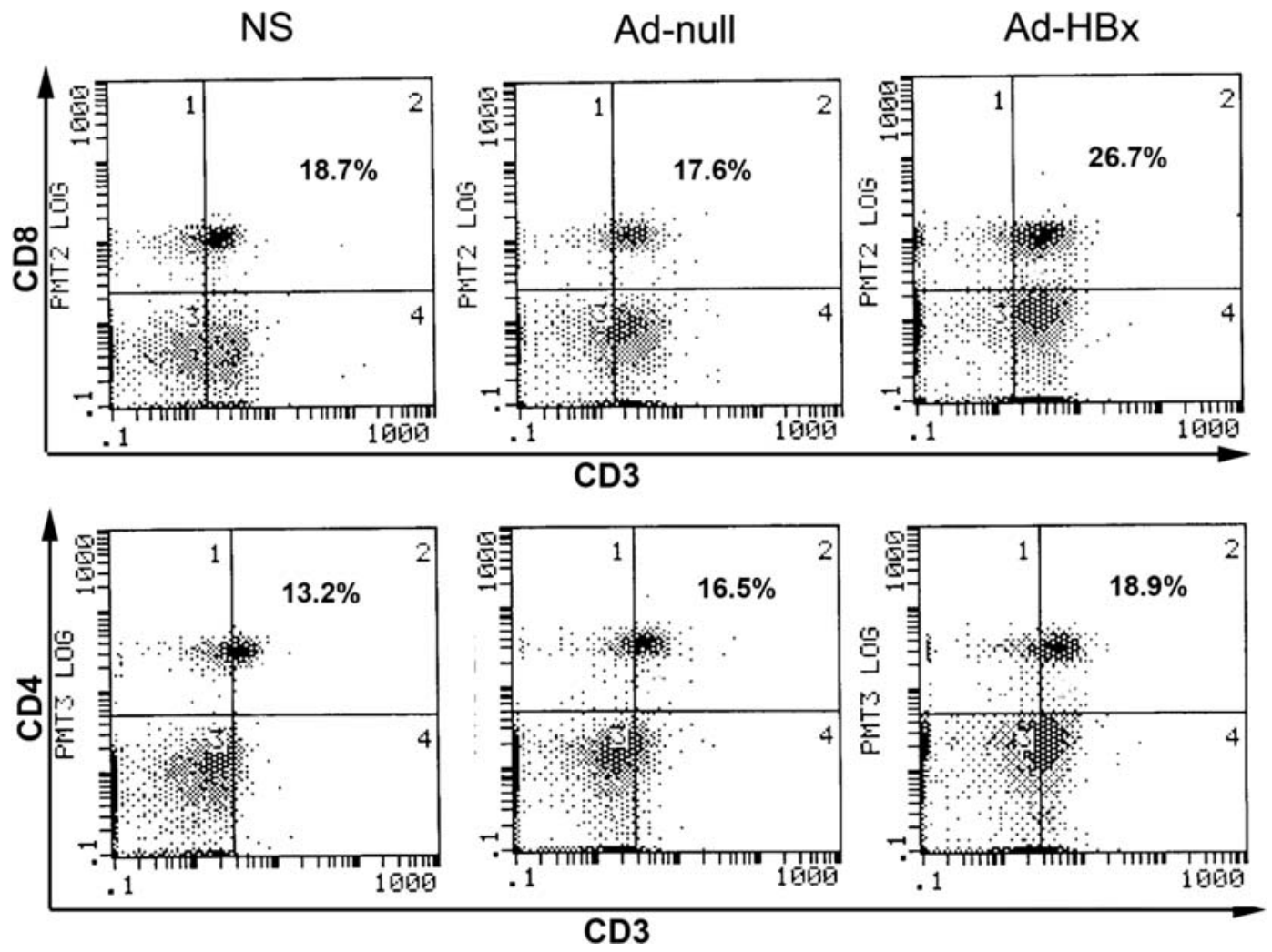

Figure 5. Characterization of the lymphocyte population. Splenocytes were isolated and stained with a combination of fluorochrome-conjugated anti-mouse CD4, anti-mouse CD8 and anti-mouse CD3. After staining, multiple-color flow analyses were performed using flow cytometer. The component of CD8 ${ }^{+} \mathrm{T}$ cell was slightly larger than that of $\mathrm{CD} 4^{+} \mathrm{T}$ cell.

with NS or Ad-Null immunized groups $(\mathrm{P}<0.01)$. To further assess the potential of the vaccines as a therapeutic agent for HCC, the survival of the mice was observed over a period of 75 days (Fig. 2B). NS-treated mice started to die of tumor progression on day 48 and all of them expired by day 66 . Adnull immunized mice started to die on day 51 and all of them died by day 69 . In contrast, $80 \%$ of mice in the Ad-HBx immunized group survived until the termination of the experiment (day 75). The differential survival rates were statistically significant by log-rank test analysis between Ad-HBx group and the control groups $(\mathrm{P}<0.01$, respectively).

Induction of therapeutic antitumor immunity. The therapeutic efficacy of adenoviral vaccines expressing HBx was next tested in the established tumors. The mice were treated starting at day 7 after the injection of HBx positive Hepa1-6 hepatoma cells, when the tumor was palpable. Significant reduction of tumor growth was observed in the Ad-HBx treated group $(\mathrm{P}<0.01)$ (Fig. 2C). The survival of the tumor-bearing mice treated with Ad-HBx was also significantly greater than that of the controls $(\mathrm{P}<0.01)$ (Fig. 2D).

Therapeutic effect on apoptosis. To better understand the relationship between antitumor effect and apoptosis of tumor cells, tumors resected 2 weeks after the completion of immunization were subjected to TUNEL assays. An apparent increase in the number of apoptotic cells could be observed in the Ad-HBx treated group (Fig. 3). Data represent the mean apoptotic index + standard deviations of cancer cells as percent normalized to apoptotic index of cancer cells (Fig. 3D).

Histological analysis. Histologically, tumors from the Ad-HBx treated group showed a significant increase in necrosis as compared with the controls. Lymphocyte infiltration was also remarkably elevated in the tumors of Ad-HBx treatment. To further detect the type of the infiltrated lymphocytes in tumors, anti-CD4 and anti-CD8 monoclonal antibodies were used in immunofluorescence staining. As shown in Fig. 4, the infiltrated lymphocytes were mainly $\mathrm{CD} 8^{+}$cytotoxic $\mathrm{T}$ lymphocytes.

Characterization of the lymphocyte population. Splenocytes were isolated from different groups and analyzed with flow cytometry. We found that the CTLs consisted of $\mathrm{CD}^{+}$and $\mathrm{CD}^{+} \mathrm{T}$ cells simultaneously. The component of $\mathrm{CD}^{+} \mathrm{T}$ cell was $26.7 \%$ in the animals that received Ad-HBx treatment which was larger than that from the NS (18.7\%) or Ad-null $(17.6 \%)$ treated groups. Slightly increased component of $\mathrm{CD}^{+} \mathrm{T}$ cells was also observed in the Ad-HBx immunized group (Fig. 5).

Induction of specific CTL response by immunization of mice with Ad-HBx. To determine whether tumor-specific CTL response could be induced in Ad-HBx-immunized mice, tumor cell cytotoxic activity of CTLs was examined. As shown in Fig. 6A, the lymphocytes from Ad-HBx-immunized mice were able to lyse specific target cells (Hepa1-6/HBx) in an 

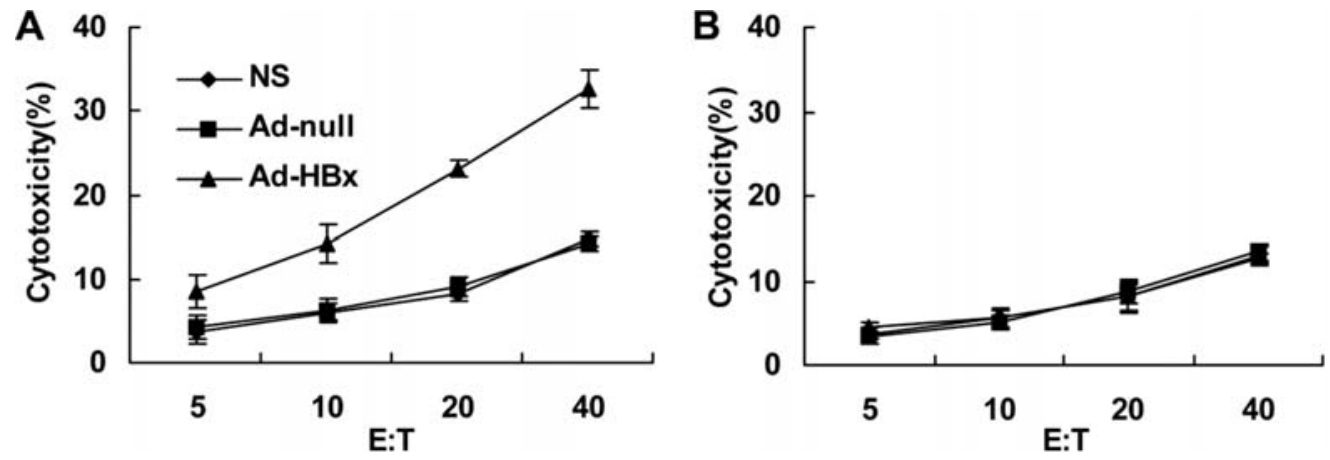

Figure 6. Induction of CTL activity by immunization of mice with Ad-HBx. The splenocytes were obtained from the mice at day 7 after the fourth immunization or from control mice as described in Materials and methods. The effector cells were incubated for $4 \mathrm{~h}$ with ${ }^{51} \mathrm{Cr}-\mathrm{labeled}$ target cells (Hepa1-6/ HBx) or negative target cells (Hepa1-6/3.1). (A) The splenocytes from Ad-HBx-immunized mice were able to lyse specific target cells (Hepa1-6/HBx) in an effector/target (E/T)-dependent manner with statistical significance at $\mathrm{E} / \mathrm{T}$ ratios $\geq 10: 1$. (B) The splenocytes from Ad-HBx-immunized mice, Ad-null-immunized mice and NS treated-mice exhibited the same cytotoxicity to irrelevant target cells (Hepa1-6/3.1). Data represent mean percentages of specific lysis in each group.
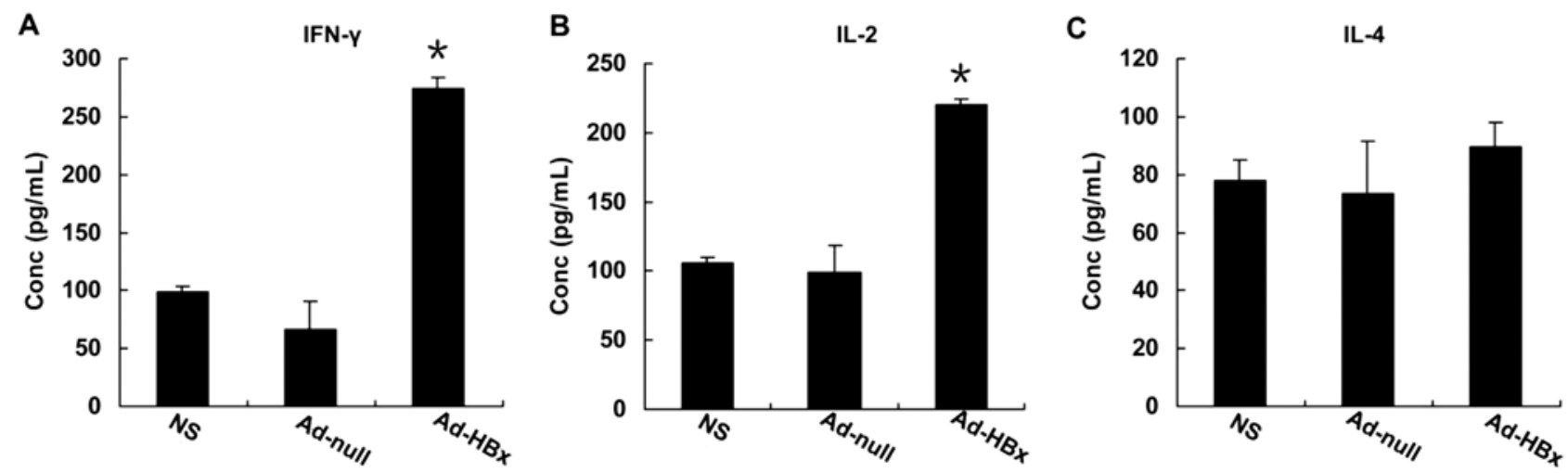

Figure 7. Characterization of cytokines. IFN- $\gamma$ (A), IL-2 (B) and IL-4 (C) were detected as described in Materials and methods. Briefly, the splenocytes were separated and restimulated. After $72 \mathrm{~h}$ at $37^{\circ} \mathrm{C}, 100 \mu 1$ of supernatant was harvested and tested for IFN- $\gamma$ and IL-2 by ELISA kit. The level of IFN- $\gamma$ and IL-2 in the supernatants harvested from the splenocytes of Ad-HBx-immunized mice was higher than that of control groups $(\mathrm{P}<0.05)$. We did not find any difference in the expression of IL-4. $\mathrm{P}<0.01$, significantly different from the normal saline (NS) or Ad-null groups.

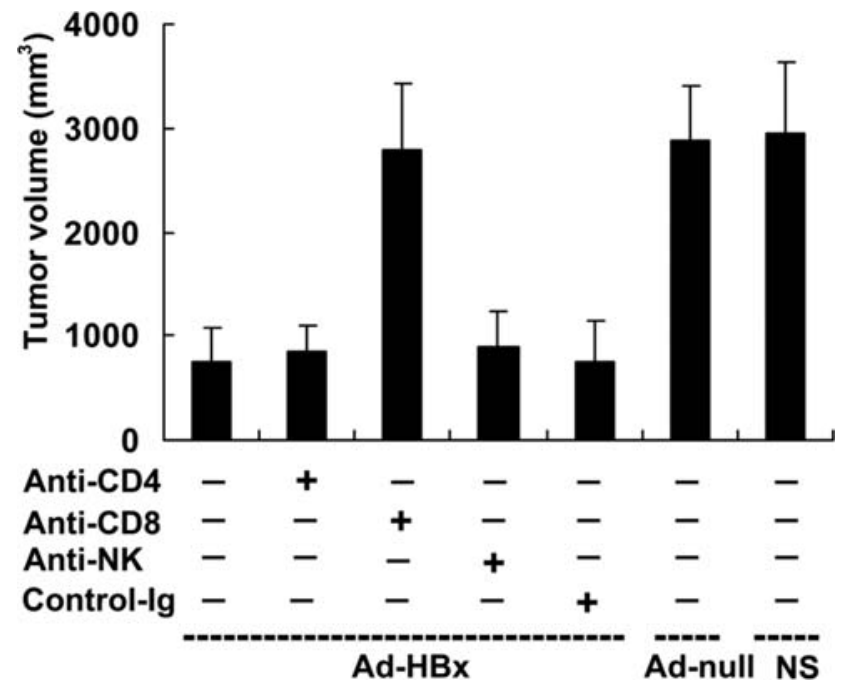

Figure 8. Abrogation of antitumor activity by the depletion of immune cell subsets. In vivo depletion of $\mathrm{CD}^{+} \mathrm{T}$ lymphocytes showed complete abrogation of the antitumor activity of the Ad-HBx vaccine. In contrast, the treatment with anti-CD4 mAb, anti-NK mAb, or control IgG showed no effect. Data reprecent day 40 after tumor cell inoculation (mean \pm SD). Similar results were found at other time points. effector/target $(\mathrm{E} / \mathrm{T})$-dependent manner with statistical significance at $\mathrm{E} / \mathrm{T}$ ratios $\geq 10: 1$. However, the lymphocytes from Ad-HBx-immunized mice, Ad-null-immunized mice and NS-treated mice exhibited the same cytotoxicity to irrelevant target cells (Hepa1-6/3.1) (Fig. 6B). These results demonstrated that HBx could induce tumor-specific CTL response in vivo.

Characterization of cytokines. The spleen cells isolated from the immunized mice or controls were re-stimulated with Ad$\mathrm{HBx}$ and supernatants were harvested. The production of IFN- $\gamma$, IL-2 and IL-4 was evaluated by ELISA. As shown in Fig. 7, the increase in the level of IFN- $\gamma$ and IL-2 was found in the supernatants harvested from the spleen cells of Ad-HBximmunized mice $(\mathrm{P}<0.01)$. We did not find any difference in the expression of IL-4.

Function of T-cell subsets in antitumor activity. To explore the roles of immune cell subsets in antitumor activity elicited by $\mathrm{HBx}$, we depleted $\mathrm{CD}^{+}$or $\mathrm{CD} 8^{+} \mathrm{T}$ lymphocytes or $\mathrm{NK}$ cells through injection of the corresponding monoclonal antibodies. Mice depleted of $\mathrm{CD} 8^{+} \mathrm{T}$ lymphocytes and 
vaccinated with Ad-HBx were not protected from tumor challenge. In contrast, treatment with mAb against $\mathrm{CD}^{+}$or NK cells failed to abrogate the antitumor activity (Fig. 8). These data suggest that $\mathrm{HBx}$-specific $\mathrm{CD}^{+} \mathrm{T}$ lymphocytes are probably responsible for the antitumor activity.

\section{Discussion}

HBV are strongly associated with the development hepatocellular carcinoma (HCC) $(24,25)$. Among the four proteins expressed by HBV genome, HBx is a multifunctional regulatory protein participating in viral pathogenesis and in $\mathrm{HBV}$-mediated hepatocarcinogenesis. It has been reported that the development of $\mathrm{HCC}$ is critically related to the expression level of HBx protein (26). Moreover, in HCC, $\mathrm{HBx}$ protein expression has a higher ratio than PreS2/S, HBV core protein $(\mathrm{HBc})$, and HBV surface protein (27). Thus, developing vaccines based on HBx protein that could elicit significant immune reactions may be a possible strategy against HBV associated carcinomas. Herein, we evaluated the antitumor immune effects of recombinant adenovirus expressing HBx mediated vaccine strategy in a murine model of HBx-positive hepatoma. The present study has, to our knowledge, first demonstrated that recombinant adenovirus encoding $\mathrm{HBx}$ as vaccine can induce both protective and therapeutic antitumor immunity against HBx-positive hepatocellular carcinoma. Importantly, the vaccine significantly prolonged the survival time of tumor-bearing animals.

The mechanism by which antitumor immune response against $\mathrm{HBx}$-positive tumors with adenovirus encoding $\mathrm{HBx}$ gene in the present study may be in part the result of eliciting the host CTL response against $\mathrm{HBx}$-associated $\mathrm{HCC}$. CD8 ${ }^{+}$ CTLs are considered important elements for protection against various virus-associated malignancies (28). In the present study, apparent infiltration of $\mathrm{CD}^{+} \mathrm{T}$ lymphocytes was observed in the tumor of Ad-HBx treated group, which suggests an onset of immune response in the local mass. Flow cytometric analysis of HBx-specific CTL populations showed that the component of $\mathrm{CD}^{+} \mathrm{T}$ lymphocytes after vaccination with Ad-HBx was larger than that of Ad-null or control groups. Moreover, the depletion of $\mathrm{CD}^{+} \mathrm{T}$ lymphocytes showed complete abrogation of the antitumor immune activity in vivo. Meanwhile, the depletion of $\mathrm{CD}^{+} \mathrm{T}$ lymphocytes or natural killer cells (NK) failed to abrogate the antitumor activity. These findings strongly support the suggestion that elicitation of $\mathrm{HBx}$-specific $\mathrm{CD} 8^{+} \mathrm{T}$ lymphocytes is responsible for the antitumor activity of the vaccine.

Previous studies have demonstrated that the antitumor immune response against tumors with vaccine may be involved in both humoral and cellular immunity (21). The findings in the present study show that splenocytes obtained from the Ad-HBx-immunized mice secreted increased level of $\mathrm{T}$ cytotoxic (Tc) 1-type cytokine (IFN- $\gamma$ and IL-2), while no difference was found in the expression of Tc 2-type cytokine (IL-4). These findings suggest that the antitumor efficacy of Ad-HBx may mostly result from cellular immunity rather than humoral immunity.

Adenoviral vectors are commonly used for gene delivery as well as vaccine carrier due to their high efficiency and high capacity. The recombinant replication-deficient adenoviral vector has several properties that make it particularly promising candidates for DNA vaccination approaches. Firstly, adenoviruses efficiently infect a variety of target cell types in vitro or in vivo, leading to high levels of protein production in situ (29). Additionally, in a variety of animal models, the inherent immunogenicity of adenoviral vectors have been documented to induce potent cellular and humoral immune responses against the product encoded by the transgene. Antiviral immunity may provide an adjuvant effect in the induction of immune response against tumorspecific antigens in cancer immunotherapy $(30,31)$. Finally, adenoviral vectors deliver tumor antigens into the endogenous antigen processing pathway that directs peptide processing and presentation onto class I MHC. This should be more potent in the activation of $\mathrm{CD}^{+} \mathrm{T}$ cells than soluble protein vaccines because soluble antigens are mostly taken up by the exogenous antigen processing pathway and presented on class II MHC (32).

Collectively, our data in the present study suggest that immunotherapy with $\mathrm{Ad}-\mathrm{HBx}$ vaccine was effective at both protective and therapeutic antitumor immunity in the hepatoma models. This antitumor effect may result from eliciting the host CTL response against $\mathrm{HBX}$-associated HCC. The present findings may be of importance in further exploration of the potential application of this vaccine in the treatment of HBV-associated HCC.

\section{Acknowledgements}

This work is supported by The National Key Basic Research Program (973 Program) of China (2010CB529900 and 2010CB529906), Hi-tech Research and Development Program (863 Program) of China (2006AA02Z488 and 2008ZX10002-023).

\section{References}

1. Bouchard MJ and Schneider RJ: The enigmatic X gene of hepatitis B virus. J Virol 78: 12725-12734, 2004.

2. Beasley RP: Rocks along the road to the control of HBV and HCC. Ann Epidemiol 19: 231-234, 2009.

3. Palmer DH, Midgley RS, Mirza N, Torr EE, Ahmed F, Steele JC, Steven NM, Kerr DJ, Young LS and Adams DH: A phase II study of adoptive immunotherapy using dendritic cells pulsed with tumor lysate in patients with hepatocellular carcinoma. Hepatology 49: 124-132, 2009.

4. Zhang Q, Chen G, Peng L, Wang X, Yang Y, Liu C, Shi W, Su C, Wu H, Liu X, Wu M and Qian Q: Increased safety with preserved antitumoral efficacy on hepatocellular carcinoma with dualregulated oncolytic adenovirus. Clin Cancer Res 12: 6523-6531, 2006.

5. Avila MA, Berasain C, Sangro B and Prieto J: New therapies for hepatocellular carcinoma. Oncogene 25: 3866-3884, 2006.

6. Zhu AX: Systemic therapy of advanced hepatocellular carcinoma: how hopeful should we be? Oncologist 11: 790-800, 2006.

7. Inchauspé G and Michel ML: Vaccines and immunotherapies against hepatitis B and hepatitis C viruses. J Viral Hepat 14 (Suppl 1): 97-103, 2007.

8. Loirat D, Lemonnier FA and Michel ML: Multiepitopic HLAA*0201-restricted immune response against hepatitis B surface antigen after DNA-based immunization. J Immunol 165: 4748-4755, 2000.

9. Tangri S, Ishioka GY, Huang X, Sidney J, Southwood S, Fikes J and Sette A: Structural features of peptide analogs of human histocompatibility leukocyte antigen class I epitopes that are more potent and immunogenic than wild-type peptide. J Exp Med 194: 833-846, 2001. 
10. Lutzky VP, Corban M, Heslop L, Morrison LE, Crooks P, Hall DF, Coman WB, Thomson SA and Moss DJ: Novel approach to the formulation of an Epstein-Barr virus antigenbased nasopharyngeal carcinoma vaccine. J Virol 84: 407-417, 2010.

11. zu Putlitz J, Encke J and Wands JR: Cytotoxic T cell responses against hepatitis B virus polymerase induced by genetic immunization. J Hepatol 33: 986-991, 2000.

12. Tang H, Oishi N, Kaneko S and Murakami S: Molecular functions and biological roles of hepatitis B virus x protein. Cancer Sci 97: 977-983, 2006.

13. Bouchard MJ, Wang L and Schneider RJ: Activation of focal adhesion kinase by hepatitis B virus HBx protein: multiple functions in viral replication. J Virol 80: 4406-4414, 2006.

14. Wang WL, London WT and Feitelson MA: Hepatitis B x antigen in hepatitis B virus carrier patients with liver cancer. Cancer Res 51: 4971-4977, 1991.

15. Chun E, Lee J, Cheong HS and Lee KY: Tumor eradication by hepatitis $\mathrm{B}$ virus $\mathrm{X}$ antigen-specific $\mathrm{CD} 8^{+} \mathrm{T}$ cells in xenografted nude mice. J Immunol 170: 1183-1190, 2003.

16. Ding FX, Wang F, Lu YM, Li K, Wang KH, He XW and Sun SH: Multiepitope peptide-loaded virus-like particles as a vaccine against hepatitis B virus-related hepatocellular carcinoma. Hepatology 49: 1492-1502, 2009.

17. Wang YJ, Hou Y, Huang H, Liu GR, White AP and Liu SL: Two oral HBx vaccines delivered by live attenuated Salmonella: both eliciting effective anti-tumor immunity. Cancer Lett 263: 67-76, 2008.

18. Cheng P, Li Y, Yang L, Wen Y, Shi W, Mao Y, Chen P, Lv H, Tang $\mathrm{Q}$ and Wei $\mathrm{Y}$ : Hepatitis $\mathrm{B}$ virus $\mathrm{X}$ protein $(\mathrm{HBx})$ induces $\mathrm{G} 2 / \mathrm{M}$ arrest and apoptosis through sustained activation of cyclin B1-CDK1 kinase. Oncol Rep 22: 1101-1107, 2009.

19. Li G, Tian L, Hou JM, Ding ZY, He QM, Feng P, Wen YJ, Xiao F, Yao B, Zhang R, Peng F, Jiang Y, Luo F, Zhao X, Zhang L, Zhou Q and Wei YQ: Improved therapeutic effectiveness by combining recombinant $\mathrm{CXC}$ chemokine ligand 10 with Cisplatin in solid tumors. Clin Cancer Res 11: 4217-4224, 2005.

20. Zhao JM, Wen YJ, Li Q, Wang YS, Wu HB, Xu JR, Chen XC, Wu Y, Fan LY, Yang HS, Liu T, Ding ZY, Du XB, Diao P, Li J, Wu HB, Kan B, Lei S, Deng HX, Mao YQ, Zhao X and Wei YQ: A promising cancer gene therapy agent based on the matrix protein of vesicular stomatitis virus. FASEB J 22: 4272-4280, 2008.

21. Lu Y, Wei YQ, Tian L, Zhao X, Yang L, Hu B, Kan B, Wen YJ, Liu F, Deng HX, Li J, Mao YQ, Lei S, Huang MJ, Peng F, Jiang Y, Zhou H, Zhou LQ and Luo F: Immunogene therapy of tumors with vaccine based on xenogeneic epidermal growth factor receptor. J Immunol 170: 3162-3170, 2003.
22. He QM, Wei YQ, Tian L, Zhao X, Su JM, Yang L, Lu Y, Kan B, Lou YY, Huang MJ, Xiao F, Liu JY, Hu B, Luo F, Jiang Y, Wen YJ, Deng HX, Li J, Niu T and Yang JL: Inhibition of tumor growth with a vaccine based on xenogeneic homologous fibroblast growth factor receptor-1 in mice. J Biol Chem 278: 21831-21836, 2003.

23. Liu JY, Wei YQ, Yang L, Zhao X, Tian L, Hou JM, Niu T, Liu F, Jiang Y, Hu B, Wu Y, Su JM, Lou YY, He QM, Wen YJ, Yang JL, Kan B, Mao YQ, Luo F and Peng F: Immunotherapy of tumors with vaccine based on quail homologous vascular endothelial growth factor receptor-2. Blood 102: 1815-1823, 2003.

24. Ganem D and Varmus HE: The molecular biology of the hepatitis B viruses. Annu Rev Biochem 56: 651-693, 1987.

25. Chisari FV and Ferrari C: Hepatitis B virus immunopathogenesis. Annu Rev Immunol 13: 29-60, 1995.

26. Dandri M, Schirmacher P and Rogler CE: Woodchuck hepatitis virus $\mathrm{X}$ protein is present in chronically infected woodchuck liver and woodchuck hepatocellular carcinomas which are permissive for viral replication. J Virol 70: 5246-5254, 1996.

27. Su Q, Schröder CH, Hofmann WJ, Otto G, Pichlmayr R and Bannasch P: Expression of hepatitis B virus X protein in HBVinfected human livers and hepatocellular carcinomas. Hepatology 27: 1109-1120, 1998

28. Duraiswamy J, Bharadwaj M, Tellam J, Connolly G, Cooper L, Moss D, Thomson S, Yotnda P and Khanna R: Induction of therapeutic T-cell responses to subdominant tumor-associated viral oncogene after immunization with replication-incompetent polyepitope adenovirus vaccine. Cancer Res 64: 1483-1489, 2004.

29. Basner-Tschakarjan E, Gaffal E, O'Keeffe M, Tormo D, Limmer A, Wagner $\mathrm{H}$, Hochrein $\mathrm{H}$ and Tüting $\mathrm{T}$ : Adenovirus efficiently transduces plasmacytoid dendritic cells resulting in TLR9-dependent maturation and IFN-alpha production. J Gene Med 8: 1300-1306, 2006.

30. Timmerman JM, Caspar CB, Lambert SL, Syrengelas AD and Levy R: Idiotype-encoding recombinant adenoviruses provide protective immunity against murine B-cell lymphomas. Blood 97: 1370-1377, 2001

31. Armstrong AC, Dermime S, Allinson CG, Bhattacharyya T, Mulryan K, Gonzalez KR, Stern PL and Hawkins RE: Immunization with a recombinant adenovirus encoding a lymphoma idiotype: induction of tumor-protective immunity and identification of an idiotype-specific T cell epitope. J Immunol 168: 3983-3991, 2002.

32. Wong CP and Levy R: Recombinant adenovirus vaccine encoding a chimeric T-cell antigen receptor induces protective immunity against a T-cell lymphoma. Cancer Res 60: 2689-2695, 2000. 